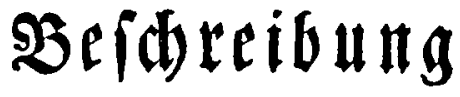

Dez

\section{\$ortugiefificen Imerifa}

bom

\section{Subena.}

\section{Ein Spanifacs Manufript}

iil

Der $\mathfrak{B o l f e n b u t t e l}$ den $\mathfrak{B}$ ibliothef, heraubgegeben

$$
\text { Sexrn Sofratg feffing. }
$$

Mit

2nmertungen uno Bufázen begleitet

won

$$
\text { Chriftian seifte, }
$$

Reftor ser Şerzoglidien grofen Sdule zu 2 Bolfenbi̊ttel.

$$
\text { Braunforeig, }
$$

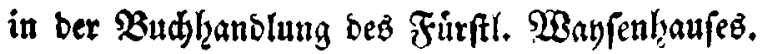

$$
\text { I } 780 \text {. }
$$

